IRA-International Journal of Management \&

Social Sciences

ISSN 2455-2267; Vol.08, Issue 02 (August 2017)

Pg. no. 142-151

Institute of Research Advances

http://research-advances.org/index.php/RAJMSS

\title{
Marginal Cost Based Lending Rate (MCLR): A Study on the New Regime of Lending Rate Pattern of the Banking Operations in India
}

\author{
Dipayan Singh \\ College Contractual Lecturer, Ramsaday College, India.

\section{Dr. Amit Majumdar} \\ Assistant Professor (III, Formerly Reader) \& Head of Dept. of Commerce, Bijoy Krishna Girls' \\ College, Howrah, India.
}

Type of Review: Peer Reviewed.

DOI: http://dx.doi.org/10.21013/jmss.v8.n2.p2

How to cite this paper:

Singh, D., Majumdar, A. (2017). Marginal Cost Based Lending Rate (MCLR): A Study on the New Regime of Lending Rate Pattern of the Banking Operations in India. IRA-International Journal of Management \& Social Sciences (ISSN 2455-2267), 8(2), 142-151. doi:http://dx.doi.org/10.21013/jmss.v8.n2.p2

(C) Institute of Research Advances.

\section{(c)) BY-NC}

This work is licensed under a Creative Commons Attribution-Non Commercial 4.0 International License subject to proper citation to the publication source of the work.

Disclaimer: The scholarly papers as reviewed and published by the Institute of Research Advances (IRA) are the views and opinions of their respective authors and are not the views or opinions of the IRA. The IRA disclaims of any harm or loss caused due to the published content to any party.

Institute of Research Advances is an institutional publisher member of Publishers Inter Linking Association Inc. (PILA-CrossRef), USA. The institute is an institutional signatory to the Budapest Open Access Initiative, Hungary advocating the open access of scientific and scholarly knowledge. The Institute is a registered content provider under Open Access Initiative Protocol for Metadata Harvesting (OAI-PMH).

The journal is indexed \& included in WorldCat Discovery Service (USA), CrossRef Metadata Search (USA), WorldCat (USA), OCLC (USA), Open J-Gate (India), EZB (Germany) Scilit (Switzerland), Airiti (China), Bielefeld Academic Search Engine (BASE) of Bielefeld University, Germany, PKP Index of Simon Fraser University, Canada. 


\begin{abstract}
Marginal cost of fund based lending rate (MCLR) is referred as an internal benchmark rate at which the banks can lend to its customers, introduced by Reserve Bank of India (RBI) with effect from $1^{\text {st }}$ April, 2016, charging different rates on the basis of different factors relating to a loan such as marginal cost of funds, Negative carry on account of Cash reserve ratio, operating cost, tenor premium. Banks shall publish internal benchmarks for time period from overnight to one year. Banks shall have the advantage to decide the external benchmark rate related to market determined external factors. Existing loan customers based on BPLR system will be provided the option to switch their loans on the basis of their will and no switching charge is to be applied. MCLR may be considered a double edged sword as referred to the base rate system which was a single edge sword to harm customers as the banks were slowly adopting decreases in base rate and quickly transmitting high interest rate to the customer. MCLR is more of a competitive rate in respect to previous rates as it considers marginal cost of procurement of funds as the banks reach efficiency rates are to be diminished keeping base rate in mind.
\end{abstract}

\title{
Introduction
}

Marginal cost of fund based lending rate (MCLR) is referred as an internal benchmark rate at which the banks can lend to its customers. The rate is determined on the basis of incremental cost of procurement of an additional rupee to the prospective borrower. MCLR was introduced by Reserve Bank of India (RBI) with effect from $1^{\text {st }}$ April, 2016.The Reserve Bank of India has asked banks to set at least five MCLR rates - overnight, one month, three month, six month and one year. For any tenure more than one year, banks are independent to set rates for longer durations. The rates have to be reviewed on a monthly basis, but banks that don't have the capacity to do monthly reviews on can do so quarterly till March 2017.

\section{Review of Literature}

Amandeep (1993) attempted to examine the trends in profits and profitability on twenty nationalized commercial banks with the help of trend analysis, ratio analysis and concentration indices of the selected parameters. The study identifies the various factors and empirical testing as to which of the identified factors have significantly contributed towards banks profitability in either direction. In conclusion she suggested in spite of lack of control of few determinants of burden, it is inferred that bank ${ }^{e e}$ profitability can significantly he enhanced by judicious management of the burden.

Srinivasan (1995) studied the experience of public sector banks in priority sector lending during the period 1969 to 1989 . The study highlighted the achievements of the banks in securing the desired allocation pattern of credit in different sectors and sub-sectors. He derived home the point that the burden of priority sector lending is borne mainly by the public sector banks and other institutional agencies. The study revealed that there was a fall in spatial and sectorial imbalances in banking operations over a period of time.

Ganesan, P (1998) In his study focused to analyze the following aspects: i) economies of priority and nonpriority sector transactions with reference to spread, burden and surplus; ii) the use of efficiency, liquidity and profitability ratios to assess the operational efficiency; iii) determinants of profitability to derive a profit, function model: and iv) the economies of scale regarding cost, production and profit functions. Finally, the study pinpoints certain ideas for the improvement of profitability and the technical change to be made to recover the over dues of priority sector advances.

Chaudhuri (2002) suggested that the public sector banks are facing triple jeopardy. First they are losing market share, second their profitability is being seriously squeezed and lastly their balance sheets are not strong and their sovereign support, which had buttressed them so far, is becoming open to question. Principle operative factor derives from the nature of their ownership and what translates in terms of goal and priorities. However, it was concluded that the public sector banks in India are neither very strong nor very weak. But they do not have any further capacity to bear the burden of pursuing government policies.

Sathishkumar Balasubramanian (2008) stated that the economic reforms totally have changed the banking sector RBI permitted new banks to be started in the private sector as per the recommendation of Narashiman committee. The Indian banking industry was dominated by public sector banks. But now the situations have changed new generation banks with used of technology and professional management has gained a reasonable 
position in the banking industry. The main idea of this article is to make an evaluation of the financial performance of Indian private sector banks.

Uppal (2010) explained that Indian banking industry has undergone qualitative changes due to banking sector reforms and felt the need to examine the efficiency of banks operating in India and concluded that profitability and productivity were much higher in the case of new private sector banks and foreign banks as compared to Indian PSBs. Even the liquidity position of the new private sector and foreign banks was also sound as compared to their counterparts. This paper suggests some possible measures to improve the efficiency of PSBs.

Mishra and Montiel (2012) survey the evidence on the effectiveness of monetary transmission in developing countries. They conclude that, despite methodological issues present in the literature, monetary transmission appears to be weak in developing countries.

Mishra et al. (2014) find large variation in the response of bank lending rates to monetary policy shocks across countries, with weaker transmission in developing countries.

\section{Objective of the Study}

The study is undertaken to represent the requirement of MCLR in respect to base rate and the applicability of the interest rate for better monetary transmission and transparency in operations to protect customers from exploitations.

- To review the evolution of MCLR

- Measurement of MCLR considering both guidelines and banks perspectives for mutual benefit of the banks and customers.

- Exemptions to MCLR

- Representation of current trends in these rates and compatibility of the guidelines.

- Analyze the current trend and competition between the banks in respect to MCLR.

\section{Evolution}

The first attempt to rationalize and administer the lending rate was made in September 1990 by evicting the complexity of interest rates. The structure constituted different progressive slabs holding progressive interest rates. The lowest slab of advances up-to Rs 7,500 with a an interest rate of $10 \%$ per annum and the highest slab of advances above two lakhs were prescribed with an interest rate of minimum $16 \%$ per annum. These prescriptions were denoted to working capital loans and term loans, while other loans constituted of other structures as preferred by individual banks. The next significant step was taken in April, 1993, where the credit limit size class of scheduled commercial banks were restructured to three slabs of up-to Rs 25,000, 25,0002,00,000 and advances over two lakhs. In October, 1994 banks were dispensed with the authority to decide its lending rate for advances over two lakhs rupees with a condition to publish their prime lending rate(PLR). PLR was determined by individual banks on the basis of cost of funds, transaction cost, etc. to lend their prime customers at an adjacent rate. But prime lending rate strategy turned out to be unfavorable, and discriminations were being made by the banks to its customers. To stem this practice the banks were instructed on a mandatory basis to publish its spread over PLR for all advances. Spread was considered to be the discriminating rate and the reasons for discrimination. Prime Term Lending Rate (PTLR) was introduced in October, 1997 which was an extension to PLR in which banks were to determine PLTR for term loans of 3 years and above. The next significant change was noticed in April, 1999 in which Tenor Linked Lending Rate (TPLR) was rolled so that banks could wield different PLR's for different advances of different time periods with the condition of maintaining all the instructions previously drafted. The Annual Policy drafted in the new millennium affirmed the banks to charge fixed or floating exchange rate on all advances of above two lakhs considering PLR as reference rate. In the year $2001 \mathrm{RBI}$ in its annual policy eased off the requirement of PLR being the floor rate for loans above two lakhs so the banks could provide loans to its credit worthy borrowers at interest rates below PLR. Again the situation of discrepancy aroused as the interest rate changes were not being reflected as interest rate changes to the customers. So RBI started to collect information relating to interest rates charged by various banks and got engaged in intensive monitoring and came up with the fact that there existed a huge gap in PLR and spread across different banks. As a result of fact, RBI in its annual statement of April 2003 instructed the banks to publish Benchmark Prime Lending Rate (BPLR) with an objective of transparency and efficient interest rates. Benchmark PLR was to be computed considering different factors like cost of funds, operational expenses, and minimum margin to cover the requirements of capital charge and profit margin. Simultaneously banks were instructed to discontinue the practice of TPLR with an exception to floating rate loans using market benchmark and time varied spread in order to enhance transparency. However the banks were dissatisfied with the instructions provided by RBI and recognized the need to manipulate the BPLR scheme as different pricing 
strategy was felt in need for different risk and charges involved in different loans. Transaction costs relating to loans were different for different sectors like consumer and corporate loans which made the banks concerned so they demanded different BPLR for different sectors. Obviously BPLR could not meet the desired expectations and resulted in

- Decrease in sub-BPLR lending- Share of sub-BPLR lending showed a gradual decrease in 2009 in respect to previous years. And this change was noticed by all scheduled commercial banks including public and private sector banks.

- Non - transparency- Banks were charging BPLR with reference to internal and non-transparent data.

- Discrepant trend- Banks were adopting rapid changes relating to higher interest rates but were slow to bring down interest rates to gain extra amount of profit and curb the interest burden on fixed interest bearing loans.

- Preferential credit offering- Corporate and highly rated borrowers were provided with a sub-BPLR due to low risk involvement and created a perception that large borrowers are being cross subsidized by retail and small customers.

In regard to neutralize the situation Base Rate system was introduced by RBI to certify a benchmark below which banks cannot lend along with an objective of emphatic transmission of interest rate policy to its customers. But the banks were not able to cope up with the changes in interest rates made by RBI and were not being transmitted in the interest payable by a customer. The base rate system turned out to be nugatory and the need to introduce MCLR was felt.

Repurchase Rate or repo rate is the rate at which banks borrow money by selling their government securities to $\mathrm{RBI}$ or in other words, the rate at which RBI furnishes money to commercial banks against the pledge of government securities as per the banks need of funds to meet their day-to-day obligations. RBI constructs the repo rate which is applicable to the banks. Repo rate being a quantitative credit control instrument has a major role in upliftment of the Indian economy. An increment in repo rate is reflected by an increment in the cost of credit boned by the customers taking loans from banks and vice versa. A cut in repo rate by RBI in its monetary policy review will imply a decrease in the cost of short term credit. A customer would predict an interest rate cut as the repo rate goes down but the actual scenario is different, lending rates of the banks are based on base rate which is fixed by the banks acting upon the guidelines provided by RBI. So, an automatic transmission of repo rate cut or hike is not reflected in the interest rate payable by a customer. The discrepancies arising led to the introduction of MCLR and improve the monetary transmission.

\section{Computation of MCLR}

- Marginal cost of funds: Represented by the cost of fresh borrowing that is payable by a bank to its customers on their deposits. Not only savings or current account deposits but term deposits and borrowings are also includes in marginal cost of funds. Cost of equity is also considered to play a pivotal role in determining marginal cost of funds. $92 \%$ of the weights are allotted to marginal cost of borrowing and the remaining $8 \%$ weightage is allotted to return on net worth.

- Negative carry on account of CRR: Cash reserve ratio is the percentage of banks deposits that are needed to be stored by RBI, at current CRR is $4 \%$ which means $96 \%$ of the amount deposited can be further invested.

- Operating costs: Costs that incur in day to day business in the course of operation in business like salary, wages, Rent etc.

- Tenor premium: Longer the duration of loan, the tenor premium tends to rise.

The risk accepted by banks in lending a loan can be referred as spread. A creditworthy customer can be provided a loan with lower spread whereas a higher spread considering the profile of the customer. For the sake of uniformity in these components, all banks shall adopt the following broad components of spread:

a. Business strategy - Considerations regarding the business strategy, market competition, embedded options in the loan product, market liquidity of the loan etc are to be kept in mind in calculating the spread.

b. Credit risk premium - The credit risk premium charged to the customer representing the default risk arising from loan sanctioned should be arrived at based on an appropriate credit risk rating/scoring model and after taking into consideration customer relationship, expected losses, collaterals, etc. 
The percentage of spread being charged to an existing borrower will not be hampered except any alteration on account of the credit risk profile of the customer. A full-fledged risk profile review of the customer is necessary in case of any alteration in calculation of spread so that transparency is achieved. MCLR will be a tenor linked benchmark program indicating the fact that different rates are to be proposed for different time period considering the components of its calculation. Banks shall publish internal benchmarks for time period from overnight to one year.

- Overnight MCLR,

- One-Month MCLR,

- Three-Month MCLR,

- Six Month MCLR,

- One Year MCLR.

In addition to the above, banks are independent of publishing MCLR of any other longer maturity. MCLR is not just an interest rate to be left once determined, banks are in obligation to review and publish its MCLR for different maturities every month on a pre-announced date with consultation with the board. A subsidized exemption is provided to banks which do not have apposite system to review monthly MCLR is required publishing their rates once a quarter on a pre-announced date for the first one year till $31^{\text {st }}$ March, 2017 with the condition of adopting monthly review there-after.

Banks shall have the advantage to decide the external benchmark rate related to market determined external factors.

Existing loan customers based on BPLR system will be provided the option to switch their loans on the basis of their will and no switching charge is to be applied. The customers who do not prefer to switch will continue on the same system and the banks will review and publish base rate simultaneously. These loans are to be continued till repayment or renewal but no new loans are to be disbursed in base rate and no loan is to be provided below MCLR.

\section{Exemptions from MCLR}

I. Loans covered by schemes specially formulated by Government of India wherein banks have to charge interest rates as per the scheme, are exempted from being linked to MCLR as the benchmark for determining interest rate.

II. Working Capital Term Loan (WCTL), Funded Interest Term Loan (FITL), etc. granted as part of the rectification/restructuring package, are exempted from being linked to MCLR as the benchmark for determining interest rate.

III. Loans granted under various refinance schemes formulated by Government of India or any Government Undertakings wherein banks charge interest at the rates prescribed under the schemes to the extent refinance is available are exempted from being linked to MCLR as the benchmark for determining interest rate. Interest rate charged on the part not covered under refinance should adhere to the MCLR guidelines.

IV. The following categories of loans can be priced without being linked to MCLR as the benchmark for determining interest rate:

a. Advances to banks' depositors against their own deposits.

b. Advances to banks' own employees including retired employees.

c. Advances granted to the Chief Executive Officer / Whole Time Directors.

d. Loans linked to a market determined external benchmark.

e. Fixed rate loans granted by banks. However, in case of hybrid loans where the interest rates are partly fixed and partly floating, interest rate on the floating portion should adhere to the MCLR guidelines.

State Bank of India the largest public sector bank operating throughout India has published its MCLR which is comparatively low than any other Indian or foreign banks. In the Table 1 below a representation of MCL Rates are made for the last six months which shows the adaptation of repo rate changes and effect of other factors in calculation of MCLR. Table 2 depicts the rates of Union Bank of India at different time periods which commonly shows a higher MCLR in respect to SBI. 
Table\#1: MCLR rates of SBI for the past 6 months

\begin{tabular}{|l|r|r|r|r|r|r|r|}
\hline SBI & \multicolumn{1}{l}{$\begin{array}{l}\text { OVERNIGHT } \\
\text { MCLR }\end{array}$} & $\begin{array}{l}\text { 1 } \\
\text { MONTH }\end{array}$ & 3MONTH & 6MONTH & 1YEAR & YEAR & 3 YEAR \\
\hline OCT & 8.65 & 8.75 & 8.8 & 8.85 & 8.9 & 9 & 9.05 \\
\hline NOV & 8.65 & 8.75 & 8.8 & 8.85 & 8.9 & 9 & 9.05 \\
\hline DEC & 8.65 & 8.75 & 8.8 & 8.85 & 8.9 & 9 & 9.05 \\
\hline JAN & 7.75 & 7.85 & 7.9 & 7.95 & 8 & 8.1 & 8.15 \\
\hline FEB & 7.75 & 7.85 & 7.9 & 7.95 & 8 & 8.1 & 8.15 \\
\hline MAR & 7.75 & 7.85 & 7.9 & 7.95 & 8 & 8.1 & 8.15 \\
\hline APR & 7.75 & 7.85 & 7.9 & 7.95 & 8 & 8.1 & 8.15 \\
\hline MAY & 7.75 & 7.85 & 7.9 & 7.95 & 8 & 8.1 & 8.15 \\
\hline JUNE & 7.75 & 7.85 & 7.9 & 7.95 & 8 & 8.1 & 8.15 \\
\hline
\end{tabular}

Source: RBI Publication and https://www.myloancare.in/

Table\#2: MCLR rates of UBI for the past 6 months

\begin{tabular}{|l|r|r|r|r|r|r|r|}
\hline UBI & $\begin{array}{l}\text { OVERNIGHT } \\
\text { MCLR }\end{array}$ & $\begin{array}{l}\text { 1 } \\
\text { MONTH }\end{array}$ & 3MONTH & 6MONTH & 1YEAR & YEAR & 3 YEAR \\
\hline OCT & 9.15 & 9.2 & 9.25 & 9.35 & 9.4 & 9.45 & 9.5 \\
\hline NOV & 9.05 & 9.1 & 9.15 & 9.25 & 9.3 & 9.35 & 9.4 \\
\hline DEC & 9.05 & 9.1 & 9.15 & 9.25 & 9.3 & 9.35 & 9.4 \\
\hline JAN & 8.15 & 8.35 & 8.4 & 8.5 & 8.65 & 8.7 & 8.75 \\
\hline FEB & 8 & 8.2 & 8.25 & 8.35 & 8.5 & 8.55 & 8.6 \\
\hline MARCH & 8 & 8.2 & 8.25 & 8.35 & 8.5 & 8.55 & 8.6 \\
\hline APR & 8 & 8.2 & 8.25 & 8.35 & 8.5 & 8.55 & 8.6 \\
\hline MAY & 8 & 8.2 & 8.25 & 8.35 & 8.5 & 8.55 & 8.6 \\
\hline JUNE & 7.9 & 8.1 & 8.15 & 8.25 & 8.40 & 8.45 & 8.50 \\
\hline
\end{tabular}

\section{Source: RBI Publication and https://www.myloancare.in/}

Private sector banks also contribute towards the loans and advances market in India. Axis and HDFC Banks are considered to be most successful among the all. These banks give neck to neck competition as they are rivals in this sector and are prevailing with an objective to earn as much as profit is possible. Creating a strong customer base will led them towards profit making through MCLR but they charge a higher rate than most of the public sector banks as their operating cost and other expenditures are higher in comparison to public sector banks.

Table\#3: MCLR rates of Axis Bank for the past 6 months

\begin{tabular}{|l|r|r|r|r|r|r|r|}
\hline AXIS & $\begin{array}{l}\text { OVERNIGHT } \\
\text { MCLR }\end{array}$ & \multicolumn{1}{l}{$\begin{array}{l}\text { MONTH } \\
\text { MONTH }\end{array}$} & 6MONTH & 1YEAR & YEAR & 3 YEAR \\
\hline OCT & 8.8 & 8.85 & 9.05 & 9.15 & 9.25 & 9.3 & 9.35 \\
\hline NOV & 8.65 & 8.7 & 8.9 & 9 & 9.05 & 9.1 & 9.15 \\
\hline DEC & 8.55 & 8.55 & 8.75 & 8.85 & 8.9 & 8.95 & 9 \\
\hline JAN & 7.9 & 7.9 & 8.05 & 8.15 & 8.25 & 8.3 & 8.35 \\
\hline FEB & 7.9 & 7.9 & 8.05 & 8.15 & 8.25 & 8.3 & 8.35 \\
\hline MARCH & 7.9 & 7.9 & 8.05 & 8.15 & 8.25 & 8.3 & 8.35 \\
\hline APR & 7.9 & 7.9 & 8.05 & 8.15 & 8.25 & 8.3 & 8.35 \\
\hline MAY & 7.9 & 7.9 & 8.05 & 8.15 & 8.25 & 8.3 & 8.35 \\
\hline
\end{tabular}

Source: RBI Publication and https://www.myloancare.in/ 
Table\#4: MCLR rates of HDFC Bank for the past 6 months

\begin{tabular}{|c|c|c|c|c|c|c|c|}
\hline HDFC & $\begin{array}{l}\text { OVERNIGHT } \\
\text { MCLR }\end{array}$ & $\begin{array}{l}1 \\
\text { MONTH }\end{array}$ & $3 \mathrm{MONTH}$ & 6MONTH & 1YEAR & 2 YEAR & 3 YEAR \\
\hline OCT & 8.85 & 8.9 & 8.95 & 9 & 9.05 & 9.15 & 9.2 \\
\hline NOV & 8.7 & 8.75 & 8.8 & 8.85 & 8.9 & 9 & 9.05 \\
\hline DEC & 8.65 & 8.7 & 8.8 & 8.85 & 8.9 & 8.95 & 9.05 \\
\hline JAN & 7.85 & 7.9 & 7.9 & 8 & 8.15 & 8.2 & 8.3 \\
\hline FEB & 7.85 & 7.85 & 7.9 & 7.95 & 8.15 & 8.2 & 8.3 \\
\hline MARCH & 7.85 & 7.85 & 7.9 & 7.95 & 8.15 & 8.2 & 8.3 \\
\hline APR & 7.85 & 7.85 & 7.9 & 7.95 & 8.15 & 8.2 & 8.3 \\
\hline MAY & 7.85 & 7.85 & 7.9 & 7.95 & 8.15 & 8.25 & 8.4 \\
\hline
\end{tabular}

Source: RBI Publication and https://www.myloancare.in/

Table\#5: Differences in MCLR rates of UBI and SBI for the past 6 months

\begin{tabular}{|c|c|c|c|c|c|c|c|}
\hline $\begin{array}{l}\text { UBI VS } \\
\text { SBI }\end{array}$ & $\begin{array}{l}\text { OVERNIGHT } \\
\text { MCLR }\end{array}$ & $\begin{array}{l}1 \\
\text { MONTH }\end{array}$ & 3MONTH & $6 \mathrm{MONTH}$ & 1YEAR & 2 YEAR & 3 YEAR \\
\hline OCT & 0.5 & 0.45 & 0.45 & 0.5 & 0.5 & 0.45 & 0.45 \\
\hline NOV & 0.4 & 0.35 & 0.35 & 0.4 & 0.4 & 0.35 & 0.35 \\
\hline DEC & 0.4 & 0.35 & 0.35 & 0.4 & 0.4 & 0.35 & 0.35 \\
\hline JAN & 0.4 & 0.5 & 0.5 & 0.55 & 0.65 & 0.6 & 0.6 \\
\hline FEB & 0.25 & 0.35 & 0.35 & 0.4 & 0.5 & 0.45 & 0.45 \\
\hline MAR & 0.25 & 0.35 & 0.35 & 0.4 & 0.5 & 0.45 & 0.45 \\
\hline
\end{tabular}

Source: RBI Publication and https://www.myloancare.in/

The above table resembles a comparison of MCLR of two giant public sector banks and the bank with low marginal and operating cost can provide loans at a lower rate of interest. A decreasing trend is noticed in the rates of Union Bank of India to cope up with SBI lending rates. True and fair representation is made on websites as per instructions made by RBI and consumers are being aware of the market rates of each bank.

Table\#6: Differences in MCLR rates of HDFC and Axis Bank for the past 6 months

\begin{tabular}{|l|r|r|r|r|r|r|r|}
\hline $\begin{array}{l}\text { HDFC } \\
\text { VS AXIS }\end{array}$ & \multicolumn{1}{l|}{$\begin{array}{l}\text { OVERNIGHT } \\
\text { MCLR }\end{array}$} & MONTH & 3MONTH & 6MONTH & 1YEAR & YEAR & YEAR \\
\hline OCT & 0.05 & 0.05 & -0.1 & -0.15 & -0.2 & -0.15 & -0.15 \\
\hline NOV & 0.05 & 0.05 & -0.1 & -0.15 & -0.15 & -0.1 & -0.1 \\
\hline DEC & 0.1 & 0.15 & 0.05 & 0 & 0 & 0 & 0.05 \\
\hline JAN & -0.05 & 0 & -0.15 & -0.15 & -0.1 & -0.1 & -0.05 \\
\hline FEB & -0.05 & -0.05 & -0.15 & -0.2 & -0.1 & -0.1 & -0.05 \\
\hline MAR & 0 & 0 & 0 & 0 & 0 & 0 & 0 \\
\hline
\end{tabular}

\section{Source: RBI Publication and https://www.myloancare.in/}

Private sector banks do play the game differently as they attract customers based on their services and services do carry cost, i.e. increasing the marginal and operational cost and concludes with a higher interest rate than other public sector banks. Rate differentiation in case of public sector banks also tends to decrease to become competitively efficient.

\section{Statistical Analysis with IBM SPSS V. 23.0}

By using SPSS the correlations of MCLR of different banks have been judged and paired sample means with 95\% confidence level have been judged. Correlation is used to describe a relationship between two variables and to verify degree of relationship. 


\begin{tabular}{|ll|r|r|}
\hline \multicolumn{2}{|c|}{ Correlations } \\
\hline SBI & Pearson Correlation & 1 & \multicolumn{1}{|c|}{ SBI } \\
& Sig. (2-tailed) & & $.989^{* *}$ \\
& $\mathrm{~N}$ & 9 & .000 \\
& Pearson Correlation & $.989^{* * *}$ & 1 \\
\hline UBI & .000 & \\
& Sig. (2-tailed) & 9 & 9 \\
\hline
\end{tabular}

The above correlation matrix compares one month MCLR of SBI and UBI to check whether a relationship exists or not. A two tailed Pearson's correlation tests have been conducted through SPSS which reflects that Pearson Correlation has a very high value of .989 which is significant at the level of 0.01 . The correlation between UBI to SBI or SBI to UBI concludes to the same correlation results.

\section{Correlations}

\begin{tabular}{|ll|r|r|}
\hline & & \multicolumn{1}{|c|}{ SBI } & \multicolumn{1}{c|}{ AXIS } \\
\hline SBI & Pearson Correlation & 1 & $.983^{* *}$ \\
& Sig. (2-tailed) & & .000 \\
& $\mathrm{~N}$ & 9 & 9 \\
\hline AXIS & Pearson Correlation & $.983^{* * *}$ & 1 \\
& Sig. (2-tailed) & .000 & \\
& $\mathrm{~N}$ & 9 & 9 \\
\hline
\end{tabular}

The same correlation tests have been applied to SBI and AXIS bank to justify the trend of MCLR and verify the degree of relationship. A decreasing trend has been noticed in respect to cope up with the market. So private players are also following the trend and competing with public sector banks. SBI and AXIS banks one month MCLR are highly correlated with a value of .983 at a significance level of 0.01 . The correlation between SBI and UBI to SBI and AXIS differs by a small fraction but follows a positive correlation.

\section{Paired Samples Statistics}

\begin{tabular}{|ll|r|r|r|r|}
\hline & & Mean & $\mathrm{N}$ & Std. Deviation & Std. Error Mean \\
\hline Pair 1 & SBI & 8.1500 & 9 & .45000 & .15000 \\
& AXIS & 8.1667 & 9 & .40697 & .13566 \\
Pair 2 & UBI & 8.5167 & 9 & .46771 & .15590 \\
& AXIS & 8.1667 & 9 & .40697 & .13566 \\
Pair 3 & SBI & 8.1500 & 9 & .45000 & .15000 \\
& HDFC & 8.1667 & 9 & .46570 & .15523 \\
Pair 4 & UBI & 8.5167 & 9 & .46771 & .15590 \\
& HDFC & 8.1667 & 9 & .46570 & .15523 \\
\hline
\end{tabular}

The above table shows the mean value of monthly MCLR rates of four different banks for 9 months data and their standard deviation and standard error.

Paired Samples Correlations

\begin{tabular}{|ll|r|r|r|}
\hline & N & Correlation & \multicolumn{1}{c|}{ Sig. } \\
\hline Pair 1 & SBI \& AXIS & 9 & .983 & .000 \\
Pair 2 & UBI \& AXIS & 9 & .982 & .000 \\
Pair 3 & SBI \& HDFC & 9 & .993 & .000 \\
Pair 4 & UBI \& HDFC & 9 & .993 & .000 \\
\hline
\end{tabular}


Paired Samples Test

\begin{tabular}{|c|c|c|c|c|c|c|c|c|c|}
\hline & & \multicolumn{5}{|c|}{ Paired Differences } & \multirow[b]{3}{*}{$\mathrm{t}$} & \multirow[b]{3}{*}{ df } & \multirow{3}{*}{$\begin{array}{l}\text { Sig. }(2- \\
\text { tailed) }\end{array}$} \\
\hline & & \multirow[b]{2}{*}{ Mean } & \multirow{2}{*}{$\begin{array}{c}\text { Std. } \\
\text { Deviation }\end{array}$} & \multirow{2}{*}{$\begin{array}{l}\text { Std. Error } \\
\text { Mean }\end{array}$} & \multicolumn{2}{|c|}{$\begin{array}{c}95 \% \text { Confidence Interval } \\
\text { of the Difference }\end{array}$} & & & \\
\hline & & & & & Lower & Upper & & & \\
\hline $\begin{array}{l}\text { Pair } \\
1\end{array}$ & $\begin{array}{l}\text { SBI - } \\
\text { AXIS }\end{array}$ & $\begin{array}{r}- \\
.01667\end{array}$ & .09014 & .03005 & -.08595 & .05262 & -.555 & 8 & .594 \\
\hline $\begin{array}{l}\text { Pair } \\
2\end{array}$ & $\begin{array}{l}\text { UBI - } \\
\text { AXIS }\end{array}$ & .35000 & .10308 & .03436 & .27077 & .42923 & 10.186 & 8 & .000 \\
\hline $\begin{array}{l}\text { Pair } \\
3\end{array}$ & $\begin{array}{l}\text { SBI - } \\
\text { HDFC }\end{array}$ & $\begin{array}{r}- \\
.01667\end{array}$ & .05590 & .01863 & -.05964 & .02630 & -.894 & 8 & .397 \\
\hline $\begin{array}{l}\text { Pair } \\
4\end{array}$ & $\begin{array}{l}\text { UBI - } \\
\text { HDFC }\end{array}$ & .35000 & .05590 & .01863 & .30703 & .39297 & 18.783 & 8 & .000 \\
\hline
\end{tabular}

The purpose of paired sample $t$ test is to detect a difference between the means of two dependent variables. The research hypothesis is that other banks follow SBBI's MCLR rate drop. The null hypothesis states that the difference between MCLR rates of banks will be less than or equal to zero. The research hypothesis states that the mean difference will be more than zero as the rates differ. The null hypothesis can be rejected as the $\mathrm{p}$ values are greater than 0.05 .

\section{Limitations of the Study}

- MCLR being a recent addition to the banking system there is lot more to study as the time passes.

- The study is conducted on secondary data so the accuracy and validity needs to be validated in real field as it varies for every different loan.

- Only few banks have been analysed in the study including public and private sector banks.

- Nine months of data could be fetched as it is a newly introduced concept.

- Time is also a limitation which restricts our study.

\section{Conclusion}

Marginal Cost Based Lending Rate may be considered a revolutionary step to eliminate lack of transparency and encourage monetary transmission of interest rate changes not only in increasing trend but also to transmit a decrease in lending rates. So it may be considered a double edged sword as referred to the base rate system which was a single edge sword to harm customers as the banks were slowly adopting decreases in base rate and quickly transmitting high interest rate to the customer. RBI guidelines regarding MCLR is focused on short term credit up-to 1 year so that customers are able to redeem the loan if not satisfactory. MCLR is more of a competitive rate in respect to previous rates as it considers marginal cost of procurement of funds as the banks reach efficiency rates are to be diminished keeping base rate in mind. Several attempts have been made previously to protect the customer from exploitation but failed. MCLR is rather a more developed attempt and its success is yet to be measured in the coming years.

\section{References}

[1] Amandeep, (1993), Profits and profitability in commercial banks, Deep \& Deep Publications. New Delhi.

[2] Balasubramanian, S. (2008) Financial Performance of Private Sector Banks in India - An Evaluation, Available at SSRN: http://ssrn.com/abstract=1044621 (last accessed on 02.05.2017).

[3] Chaudhuri S. (2002) Some Issues of Growth and Profitability in Indian Public Sector Banks, Economic and Political Weekly, Vol. XXXVII, No 22, June 1-7, Pp 2155-62.

[4] Ganesan, P.(1998) A study of priority Sector Advances vis-a-vis profits and profitability of public sector banks in India, Ph.D. Thesis. Bharathiar University, Coirnbatore.

[5] Mishra, P. and Montiel, P. (2012), How effective is monetary transmission in developing countries? A survey of the empirical evidence, November, 2012, (IMF Working Paper No.12/143), Economic Systems, 2013, Elsevier, Vol. 37(2), pp. 187-216.

[6] Mishra, P., Montiel, P., Pedroni,P., and Spilimbergo,A. (2014), Monetary policy and bank lending rates in low-income countries: Heterogeneous panel estimates, July, Journal of Development Economics, https://ideas.repec.org/a/eee/deveco/v111y2014icp117-131.html

(last accessed on 11.08.2017) 
[7] Reserve Bank of India (2014), Addressing Impediments to Transmission of Monetary Policy, Chapter 4 of Report of the Expert Committee to Revise and Strengthen the Monetary Policy Framework.

[8] Srinivasan, R. (1995), Priority sector lending: A study of Indian experience, Himalaya Publishing. New Delhi, pp. 68-72.

[9] Uppal, R.K. (2010) Indian banking: Emerging issues and enhancing competitive efficiency, The IUP Journal of Business Strategy, Vol. 7, Nos. 1 \& 2, pp. 71-82. 